\title{
The Role of Medical Students During a Pandemic: A Duty or a Choice
}

DEREK SOLED (D)

${ }^{*}$ Author affiliations can be found in the back matter of this article
凹

Levy

Library

Press

\section{ABSTRACT}

During a pandemic, it is unclear whether medical student participation in clinical responsibilities should be mandatory or voluntary. While many students have shown an interest in participating in the response to disasters, including pandemics, the number is not one hundred percent. This eagerness to serve should be lauded and appreciated, but it must not be misconstrued with a duty to act when one does not reasonably exist. It has long been held that physicians, as professionals, hold a duty to act because of their responsibility to society. Ethicists argue that, even when risks to the physician are present, their unique ability to heal supersedes these risks to themselves. From this, it can be assumed that the duty to heal for a student should be determined by their individual abilities as well as the ways in which they would be able to assist during the pandemic. A thoughtful ethical analysis leads to two possible positions regarding the duty of a medical student. In the first position, students are seen as either not having the same abilities as physicians or as existing on a spectrum between lay-people and physicians. In either case, students could not have the same duties as physicians if they did not have the same abilities, though one could argue that they should practice up to their current abilities just as physicians are required to. According to the second view, which is based on philosopher Judith Jarvis Thomson's analysis of obligation, it is mandatory that everyone do what they can to avoid moral indecency (Figure 1). In this case, students have a duty to act up to their current abilities, and to do otherwise would be indecent when the state of the world requires their assistance (Figure 2). To prevent students who want to volunteer simply due to their role as a trainee should be seen as unethical. Rather, in order to avoid moral indecency, we should carefully weigh the benefit each specific student can bring given their level of training to the amount of supervision required for their activities. 


\section{Analysis of Obligation}

- Philosopher Judith Jarvis Thomson: Everyone should do what they can to avoid moral indecency.

\section{What is moral indecency? \\ I define it as a conscious awareness that you could be doing more, or knowingly doing less than you are capable of.}

- In this case, students have a duty to act up to their current abilities, and to do otherwise would be indecent.

- To take it one step further, to prevent students from performing up to their abilities could be considered morally indecent and unethical.

\section{Medical students have an ethical obligation to perform up to their level of training.}

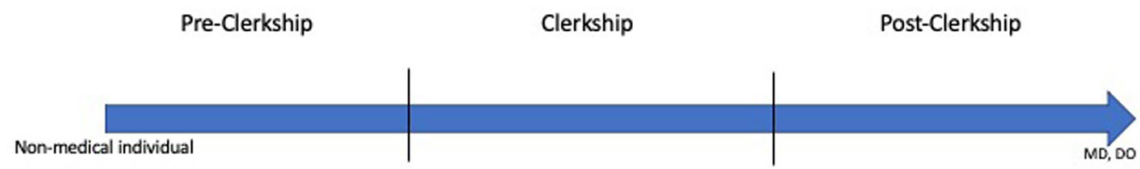

$1^{\text {st }}$ year student

$2^{\text {nd }} / 3^{\text {rd }}$ year student

$4^{\text {th }}$ year student

Duty
STM Journal of Science

and Medicine

DOI: $10.29024 /$ ijsm.29

Figure 1 Philosophical framework.

Figure 2 Ethical obligation to perform to level of training.

\section{COMPETING INTERESTS}

The author has no competing interests to declare.

\section{AUTHOR AFFILIATION}

Derek Soled (D) orcid.org/0000-0002-2714-2581

Harvard Medical School, Harvard Business School, US

\section{COPYRIGHT:}

(c) 2021 The Author(s). This is an open-access article distributed under the terms of the Creative Commons Attribution 4.0 International License (CC-BY 4.0), which permits unrestricted use, distribution, and reproduction in any medium, provided the original author and source are credited. See http://creativecommons.org/ licenses/by/4.0/.

ISMMS Journal of Science and Medicine is a peer-reviewed open access journal published by Levy Library Press. 